\title{
Editorial for advanced energy storage and conversion materials and technologies
}

\author{
Jian-Min Ma*, Yu-Tao Li*
}

Published online: 30 July 2020

(c) The Nonferrous Metals Society of China and Springer-Verlag GmbH Germany, part of Springer Nature 2020

Energy storage and conversion technologies have attracted increasing attention from academic and industrial communities due to the large demands from wide-ranging applications. Designing and developing high-performance electrode materials are cruciual to improve the performance of energy storage and conversion devices. At present, various energy storage and conversion devices, i.e., potassium-ion batteries (PIBs), sodium-ion batteries (SIBs), lithium-ion batteries (LIBs), lithium-metal batteries (LMBs), lithium-sulfur batteries (LSBs), electrochemical capacitors (ECs), have been well developed, and their corresponding electrode materials still need to be updated for obtaining superior electrochemical performance.

Here, we are greatly honored to be as Guest Editors of the journal "Rare Metals" to present the special issue on "Advanced Energy Storage and Conversion Materials and Technologies". This special issue includes contributions from twelve groups whose researches range from various rechargeable batteries. Four review articles present overviews on anode materials for sodium-ion batteries. Eight research paper results on electrode materials of ECs, LIBs, SIBs, LSBs as well as the solid-state electrolytes for LMBs.

The main contents in this issue are as follows:

\section{J.-M. Ma*}

School of Physics and Electronics, Hunan University, Changsha 410082, China

e-mail: nanoelechem@hnu.edu.cn

\section{Y.-T. Li*}

Materials Science and Engineering Program and Texas Materials Institute, The University of Texas at Austin, Austin, TX 78712, USA

e-mail: lytthu@utexas.edu
PIBs are regarded as one of promising low-cost energy storage technologies. Achieving long cycle life and high energy density has been considered as important tasks for developing high-performance PIBs. The alloy-based anodes for PIBs have attracted great attention because of their high theoretical capacity and relatively low operating voltage. The latest advance in the related alloy-based anodes was overviewed, and the correlations among the morphology and potassium storage performance, phase transition mechanisms, the formation of solid electrolyte interphases, and ionic transport kinetics were discussed by Ma et al. [1]. And the recent research progresses on the synthesis methods, electrochemical performance, reaction mechanisms, and structure-activity relationships of the alloy-based anodes for PIBs were summarized by Li et al. [2].

SIBs is considered as a promising alternative to the widely used LIBs in view of the abundant resources and uniform distribution of sodium on the earth. In a large number of anode material libraries, tin-based materials with alloying reaction mechanisms show great potential for application in high-energy SIBs due to their high theoretical-specific capacity. Detailed and comprehensive research progress on tin-based anodes (including tin metal, tin alloy, as well as its compounds) in recent years is summarized by Zhang et al. [3]. Hard carbon has been expected to the first commercial anode material for SIBs. Among various hard carbon materials, plant-derived carbon is prominent because of abundant source, low cost, and excellent electrochemical performance. A review by Wang et al. [4] gives an overview of the recent progress in the development of plant-derived hard carbon anodes for SIBs.

Transition metal phosphides (TMPs) are recognized as such promising supercapacitor materials for the practical application, due to their superior electrical conductivity 
and excellent redox activity. In this issue, self-supported three-dimensional NiCoP nanoparticles embedded in $\mathrm{NiCoO}_{2}$ nanowires $\left(\mathrm{NiCoO}_{2} / \mathrm{NiCoP}\right)$ electrode consisting of nickel cobalt phosphides $(\mathrm{NiCoP})$ with high activity and nickel-cobalt oxides $\left(\mathrm{NiCoO}_{2}\right)$ with excellent stability were fabricated, and the electrochemical performances were reported by Zhang et al. [5].

Owing to the unlimited distribution of sodium resources and similar intercalation mechanism to LIBs, SIBs are increasingly studied as the next generation of secondary batteries. Polyanion-type inorganic compounds attract much interest due to their tunable operating voltage. In this issue, a flake-structured $\mathrm{Co}_{2} \mathrm{~B}_{2} \mathrm{O}_{5}$ material was obtained by a simple sol-gel method. It is the first time that the $\mathrm{Co}_{2} \mathrm{~B}_{2} \mathrm{O}_{5}$ material was used in sodium-ion batteries by Wang et al. [6].

Hard carbon is the most promising anode for SIBs due to the wide availability and low-work voltage. However, it often delivers worse electrochemical performance in esterbased electrolytes. In this issue, a hierarchically porous loose sponge-like hard carbon with a highly disordered phase was prepared from the biomass of Platanus bark. The electrochemical performances and the charge transfer kinetics in the material were reported by Chen et al. [7].

Currently, $\mathrm{Ti}_{2} \mathrm{Nb}_{10} \mathrm{O}_{29}$ is considered to be a promising anode for LIBs due to its large theoretical capacity and high working potential, which is beneficial for achieving high energy density and improved safety. Nevertheless, $\mathrm{Ti}_{2} \mathrm{Nb}_{10} \mathrm{O}_{29}$ has a low $\mathrm{Li}^{+}$diffusion coefficient, which can lead to poor rate ability and accordingly, severely hinder its practical application in EVs/HEVs. Liu et al. [8] prepared $\mathrm{Ti}_{2} \mathrm{Nb}_{10} \mathrm{O}_{29} / \mathrm{C}$ nanoparticles with a carbon content of $13 \mathrm{wt} \%$ and a mean size of $50 \mathrm{~nm}$ through a convenient and effective in situ sol-gel process. The small grain size and carbon modification can improve the pseudocapacitive effect of the $\mathrm{Ti}_{2} \mathrm{Nb}_{10} \mathrm{O}_{29} / \mathrm{C}$ nanoparticles, leading to excellent rate capacity, especially at a high current rate.

Recently, MOFs have been recognized as promising precursors and templates for the preparation of porous transition metal oxides/carbon materials through calcining in an inert atmosphere. In this issue, hierarchical mesoporous were in situ prepared through the pyrolysis of a post-treated MIL-53(Fe) precursor by Lv et al. [9]. The hierarchical foam-like $\mathrm{Fe}_{3} \mathrm{O}_{4} @ \mathrm{C}$ nanofoams effectively relieve the volume change during the lithiation/delithiation process and facilitate fast lithium-ion and electron transport.

Recently, $\mathrm{CoCO}_{3}$ has attracted enormous attention as anodes for LIBs, benefiting from its high theoretical capacity and simple synthesis. However, the modest electronic conductivity and structural instability over cycling hinder its wider applications. To well address the intrinsic issues, Yuan et al. [10] explored a precipitant-free hydrothermal methodology for mass production of spindlelike $\mathrm{CoCO}_{3} /$ reduced graphene oxide $\left(\mathrm{S}-\mathrm{CoCO}_{3} / \mathrm{rGO}\right)$ toward advanced LIBs as a hybrid anode. The dimethylformamide plays a significant role in "two birds with one stone", in the formation of the $\mathrm{S}-\mathrm{CoCO}_{3} / \mathrm{rGO}$, greatly improving its practical applicability.

Solid-state electrolytes in rechargeable all-solid-state LMBs, which have better safety and higher specific capacity than conventional rechargeable Li-ion batteries with liquid electrolytes, are limited by the low Li-ion conductivity of the solid electrolyte and the large electrolyte/electrode interfacial resistance. In this issue, Yin et al. [11] reported a new rhombohedral NASICON structure $\mathrm{Li}_{1.4} \mathrm{Sr}_{0.2} \mathrm{Hf}_{1.8}\left(\mathrm{PO}_{4}\right)_{3}$ with a high Li-ion conductivity and showed outstanding electrochemical performances in all-solid-state Li-metal batteries.

LSBs have received much concern as emerging highpower energy storage systems. Nevertheless, the low conductivity of sulfur and polysulfide shuttle results in low rate capability and rapid capacity decay, which seriously limit its commercial application. In this issue, facile, sustainable, and cost-effective strategy for preparing heteroatom-doped porous activated carbon (PAC) derived from biomass palm kernel shell (PKS) was developed by Ma et al. [12] for high-performance LSB applications.

We would like to sincerely thank all the reviewers for their valuable contribution that ensured the original research or the high-quality reviews to be published in this special issue. We hope that this special issue will bring the readers some representative views and exciting results in battery and electrochemical capacitor materials and technologies. In addition, we believe that the special issue can give the readers some insights on advanced energy storage and conversion materials and technologies.

\section{References}

[1] Qi SH, Deng JW, Zhang WC, Feng YZ, Ma JM. Recent advances in alloy-based anode materials for potassium ion batteries. Rare Met. 2020. https://doi.org/10.1007/s12598-02001454-w.

[2] Lei KX, Wang J, Chen C, Li SY, Wang SW, Zheng SJ, Li FJ. Recent progresses on alloy-based anodes for potassium-ion batteries. Rare Met. 2020. https://doi.org/10.1007/s12598-02001463-9.

[3] Liang JM, Zhang LJ, XiLi DG, Kang J. Research progress on tin-based anode materials for sodium ion batteries. Rare Met. 2020. https://doi.org/10.1007/s12598-020-01453-x.

[4] Yu P, Tang W, Wu FF, Zhang C, Luo HY, Liu H, Wang ZG. Recent progress in plant-derived hard carbon anode materials for sodium-ion batteries: a review. Rare Met. 2020. https://doi.org/ 10.1007/s12598-020-01443-z.

[5] Ning WW, Chen LB, Wei WF, Chen YJ, Zhang XY. $\mathrm{NiCoO}_{2} /$ NiCoP@Ni nanowire arrays: tunable composition and unique 
structure design for high-performance winding asymmetric hybrid supercapacitors. Rare Met. 2020. https://doi.org/10.1007/ s12598-020-01374-9.

[6] Chen H, Xu BB, Ping QS, Wu BZ, Wu XK, Zhuang QQ, Wang $\mathrm{HL}$, Wang BF. $\mathrm{Co}_{2} \mathrm{~B}_{2} \mathrm{O}_{5}$ as an anode material with high capacity for sodium ion batteries. Rare Met. 2020. https://doi.org/10. 1007/s12598-020-01383-8.

[7] Wang XK, Shi J, Mi LW, Zhai YP, Zhang JY, Feng XM, Wu ZJ, Chen WH. Hierarchical porous hard carbon enables integral solid electrolyte interphase as robust anode for sodium-ion batteries. Rare Met. 2020. https://doi.org/10.1007/s12598-02001469-3.

[8] Liu GY, Zhao YY, Tang YF, Liu XD, Liu M, Wu PJ. In situ sol-gel synthesis of $\mathrm{Ti}_{2} \mathrm{Nb}_{10} \mathrm{O}_{29} / \mathrm{C}$ nanoparticles with enhanced pseudocapacitive contribution for a high-rate lithium-ion battery. Rare Met. 2020. https://doi.org/10.1007/s12598-02001462-w.

[9] Li HH, Saini A, Xu RY, Wang N, Lv XX, Wang YP, Yang T, Chen L, Jiang HB. Hierarchical $\mathrm{Fe}_{3} \mathrm{O}_{4} @ \mathrm{C}$ nanofoams derived from metal-organic frameworks for high-performance lithium storage. Rare Met. 2020. https://doi.org/10.1007/s12598-02001466-6.

[10] Wang YY, Zhao ZW, Liu Y, Hou LR, Yuan CZ. Precipitant-free solvothermal construction of spindle-like $\mathrm{CoCO}_{3}$ /reduced graphene oxide hybrid anode toward high-performance lithium-ion batteries. Rare Met. 2020. https://doi.org/10.1007/s12598-02001464-8.

[11] Li QH, Xu C, Huang B, Yin X. $\mathrm{Sr}^{2+}$-doped rhombohedral $\mathrm{LiHf}_{2}\left(\mathrm{PO}_{4}\right)_{3}$ solid electrolyte for all-solid-state Li-metal battery. Rare Met. 2020. https://doi.org/10.1007/s12598-020-01441-1.

[12] Han XR, Guo XT, Xu MJ, Pang H, Ma YW. Clean utilization of palm kernel shell: sustainable and naturally heteroatom-doped porous activated carbon for lithium-sulfur batteries. Rare Met. 2020. https://doi.org/10.1007/s12598-020-01439-9.

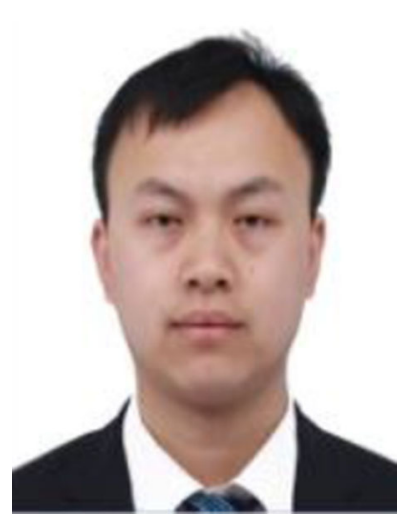

Jian-Min Ma is an associate professor in the Hunan University, Changsha, China. He received his B.S. degree in Chemistry from the Shanxi Normal University in 2003 and $\mathrm{Ph} . \mathrm{D}$. degree in Materials Physics and Chemistry from Nankai University in 2011. During 2011-2015, he also conducted the research in several overseas universities as a postdoctoral research associate. He serves as the Associate Editor for Rare Metals, and editorial board members for Journal of Energy Chemistry, Chinese Chemical Letters, Nano-Micro Letters, Journal of Physics: Condensed Matter, and others. His research interest focuses on the energy storage devices and components including metal anodes and electrolytes, and theoretical calculations from Density Functional Theory and Molecular Dynamics to Finite Element Analysis. He has published over 200 peer-reviewed papers.

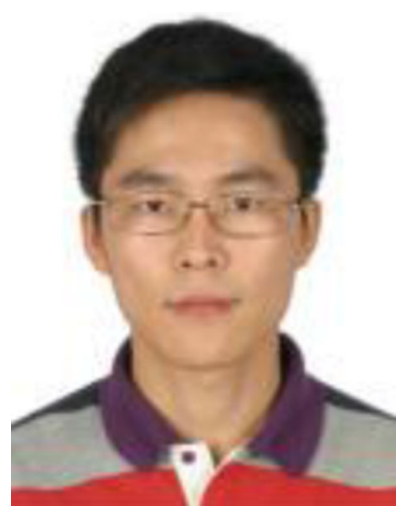

Yu-Tao Li is a research fellow at the University of Texas at Austin in the USA. He received his Ph.D. degree in Materials Science and Engineering from Tsinghua University in 2013. Now, he is working with Prof. John B. Goodenough to do the research work about transitional metal oxides and their application in batteries and catalysts. 